\title{
Transformational Leadership and Economic Development in Saudi Arabia
}

\author{
Dr. Fahad Saad Soliaman Algorabi Alharbi ${ }^{1 *}$, Dr. Mazen Mohammed Farea ${ }^{2}$ \\ Ministry of Education, Salahuddin 12434, P.O. 14811 Riyadh, Saudi Arabia ${ }^{1}$ \\ Department of Management, Al-Madinah International University, 57100 Kuala Lumpur, \\ Malaysia. ${ }^{2}$ \\ *Corresponding author, \\ Email address: Fahadclass1435@gmail.com
}

\begin{abstract}
This research aimed to explore how transformational leadership factors can be linked to the economic development in the central region of Saudi Arabia. In the current study, we had systemically selected 377 individuals with random job samples in both the public sector and private sector, by managers or vice-managers, from the central area, Saudi Arabia. through the survey frame, a technique and survey methods for gathering data on research issues; transformational leadership, and economic development were included in the current study. There were major statistically significant positive correlates of growth between idealized effects and individualized considerations, and poor significant correlations with intellectual stimulus and encouragement. The body of knowledge that studies productive and sustainable management raised the perspectives of economic development; therefore, the managers used this knowledge as a lever to accomplish it. Organizations should teach their executives and administrators to exercise leadership, make them work harder, provide good leadership, and grow their organization.
\end{abstract}

Keywords: Lean Knowledge Economy, Industrial Innovation, Visionary Leadership, Liberty and Social Cohesion, Saudi Arabia. 


\section{Introduction}

As opposed to the one-dimensional economic development that only measures quantitative shifts, economic development is a complex expression that considers qualitative and quantitative changes such as the restructuring of the production system with the implementation of modern strategies for handling capital. If I understand it, as the economy develops and expands in all areas, the economy grows in the way I am learning it does, P. Kubiczek, (2016). Bellu (2011). Research's has shown that the first step in improving a given procedure is to include a sequence of qualitative improvements. For example, the step of a qualitative improvement may be that the mechanism should be interpreted as what happens to $1^{\text {st }}$ do $2^{\text {nd }}$.

The studies of J.V. Downton (1973) and J.M. Burns (1978) concentrated on the leadership of these policymakers that had transformed the ideas of leadership, meaning that they had changed the state of the leader's thinking and the sort of decisions and actions that were to follow. The first concept is "Recommended Influence" in which the jobs are perceived to be role models. Second, intellectual stimulus provides people with the opportunity to free up their mind from routine thought and enable them to be aware of new ways of performing, solving a challenge, thinking beyond the box, and going the extra mile, S.S. Ananthan (2014). The third quality for managers is inspiring. This is where a boss has enough energy to draw the other people into the goal. To be effective, this common goal of the organization needs to be communicated with the people with this drive, S.S. Ananthan (2014). The fourth element to consider is "individualized consideration" referring to the educational promotion of empowerment of the patient, as well as the individualized expectations and ideals, B. Bass et al. (2003).

In this current article, we set out to extend the paradigm that involves transformative leadership, economic development over the economy, and to see the changes of the Saudi economy over the years. The thesis discussed some of the following key issues:

1. There is a statistically significant relationship between idealized influence economic development.

2. There is a statistically significant relationship between inspiring motivation and economic development. 
3. There is a statistically significant relationship between intellectual stimulation and economic development.

4. There is a statistically significant relationship between individualized consideration and economic development.

\section{Theoretical Background}

\section{Idealized Influence (II) on Economic Development (ED)}

The ideal effect can be defined as the ability of the leader to be the highest example of subordinates, subordinate to the commander and obeying his orders and demands. The ideal Influence is behaviour that encourages subordinates to find the values that provide them and inspire them with the meanings of their work.( Mari, 2008) praised the importance of having the ideal leader with high levels of perseverance, morale and moral values that make everyone around him influenced by his abilities to raise the values of subordinates by providing the ideal vision and deep sense of the message and not using it Achieves his personal interests. The power of confidence, characterized by a great deal of loyalty, commitment and the respect of the leader and his message, and the acceptance of values, goals, actions, religion, and honesty of the leadership, as well as a condition that is influenced by the leader, is reflected by the idealism (Daft, 2008; Eliyana, Arif \& Muzakki, 2019).

\section{Motivation (M) on Economic Development (EC)}

To motivate the enthusiasm of their followers, leaders are motivated to articulate an ambitious and imaginative dream and to foster a climate of psychological protection that encourages supporters to take emotional chances and to energize their base to beyond expectations. I may not believe that written notes are effective tools for communicating with the group. Instead, I believe that they help workers to review their challenges, make them a part of the environment and introduce them to new strategies of addressing them, Shamir, House, and Arthur, 1993, and Nakabashi (2018), investigated the implementation of the processes proposed to fight against poverty over the whole course between 1980 and 2015, among the Brazilian states. Most research on the effects of poverty look at the influence on poverty, economic development, and prosperity in the country, but barely one is assessing or attempting to quantify the impact of poverty on economic development in a country. 
That research paper demonstrates the significance of the effect of poverty on the economic development of the countries of Brazil. Although Brazil's states have a greater ratio of human resources to physical capital and productive capital to total capital, these earnings decrease per capita. With the variables which quantify extreme poverty in Brazil being more important than the ones which determine poverty in correlation with economic development, the analyses show that Brazil is currently more victim to extreme poverty.

\section{Intellectual Stimulation on Economic Development}

With the new stimulus, just as all the type of intellectual stimulation is a mechanism that is concerned with a quest for new thoughts, new methods, and means such that work can be performed with all activity and motivation and the search for new ways to complete the tasks within the creative imagination in all activities and ingenuity in it. According to Kirkland (2011), a leader who is skilled at promoting mental arousal increases conflict among members of his organization by asking a group member to re-examine the criticism that was made and encourage a better perspective on the work that the members are doing, propose a new method of approaching challenges, and encourage other members of the group to think and do the same. C. Levicki (1998) had recognized that the transformational leader will build an environment that participants feel comfortable as they propose their new proposals for implementation and that these atmospheres, along with feelings of being submissive in the leader's position, indeed strengthen the sense of subordination in the leader's role that the leader performs. To analyse the cause and effect of economic devlopment on poverty in Brazil over the years 1980-2015, the researchers examined the correlation between poverty and economic progress all over the six Brazilian states. There is almost no one to quantify the impacts of global growth and economic prosperity as it comes to poverty incidence; moreover, there is almost no one who is attempting to measure the influence of poverty prevalence on economic development. The study from this paper shows that poverty prevalence is one of the largest factors in the economic devlopment of the Brazilian States. Some of the poorest states in Brazil have lower wages per worker even though we control spending on physical resources, human capital stock, and the successful depreciation of capital. The findings refer to the variables calculating severe poverty as having a greater impact on the economic devlopment of the Brazilian States in comparison to the variables that measure poverty. 


\section{Individualized Consideration on Economic Development}

It might be said that particular considerations of individual interests and individual abilities and capacity to evolve and improve individual working people are the state of concern of each working person and their ability and skills. This emphasized that each concern is a series of conducts by which the leader should provide individual focus through specifying the needs and expectations for each topic and by taking individual differences between subordinates into account while meeting these needs (Biech, 2008). The analysis of Bass and Avolio (1997)'s study of Jordanian managers, focuses on leadership results; these outcomes were tested to ascertain what effects the leadership styles have on the actions of these Jordanian managers in business banks (Bass and Avolio, 1997). As a case study, many Henan Province colleges, and universities have studied how higher institutions serve the local economy, W. Liu (2018) paper offered a fresh perspective on the associations between China's regional economy and higherlevel institutions. Looking at local data, the results indicate that higher learning incorporating regional economic development requirements can advance internal institutional change, reinforce the connection between institutions and society, and achieve very good results in improving discipline, especially institutional development. With regards to promoting the social safety and quality of the electronic cigarette industry, they would further create a solid system for social assessment and supervision.

\section{Methodology}

\section{Research Design}

When doing the study, research architecture is a feature of which the data collection and data processing phase is a course of action that is a road-map. The study you are doing as described may be distinguished from descriptive, experimental, and exploratory science. Often an individual would want to simply be able to learn from a community of people, from a book, or through the internet. The analysis used four types of questionnaires (a questionnaire, survey, interview, and portfolio) to gather data. As an example, the survey method can be used as an indirect measurement to quantifying and infer beliefs, habits, and other aspects of a community, J.W. Creswell, (1994). 
The first step of the analysis involved the recognition and understanding of the problem statement, the establishment of the study goal, and the implementation of the research plan. The Literature Survey has been divided into two phases, the first being an illustrated analysis. Until the third step, the company had to gather data from different backgrounds, or teachers, and the parents of the students. To make the questionnaire easier to read and use, a few of the expert's suggestions were included with the new version. The pilot project aimed to try and demonstrate that the questionnaire questions were appropriate and simple to address to better accomplish the study's purpose. Besides, it was necessary to ensure that both government and non - government knowledge helped meet study goals. The updated form (questionnaire) of the pilot research was then reviewed. It was worthy to see. The last section of the questionnaire was sent to everybody. Data interpretation, dialogue, and explanations were the sixth stages in the investigation. More analysis will be performed in a descriptive manner where characteristics of the participants will be described and the measures, ratios, means, and standard deviations (arithmetic and/or geometric) of the structures employed will be measured. A technique and survey methods for gathering data on research issues, A technique and survey methods for gathering data on research issues; transformational leadership, and economic development are included in this study. In this case study. While a cross-sectional analysis using a data collection tool is intended to be utilized with a wide group of people, for example, can be done conveniently because it is relatively cheap and available, Sekaran and Bougie (2016). At the end of the final analysis, the results were outlined, concluded, and proposed.

\section{Population and Sampling}

Samples are drawn from a larger category to draw inferences regarding the population of the survey. According to Morgan and Harmon (1999), it is essential to choose representatives who are as close as possible. The researchers from this analysis had a systemically selects sampling of 377 from the survey frame, Cooper and Schindler (2011) and J.W. Creswell, (1994). In this analysis, the sub-sample is a selected random job sample in the Central region, in the public sector and private sector, by managers or vice-managers.

As a display of public records, as a result of the Ministry of Human Capital, there are about a thousand executives and administrators working in the private and public sectors in Central Area, Social Insurance system (2019). 


\section{Results and Discussion}

\section{Data Screening}

Although the first dataset consisted of an information composition (IC) that depicted responses captured in the light of the Liker scale, which ranged from unmistakably and varied from the Concurrent. The question should have been moved to numeric details because it strongly disagrees in the same way as $\mathrm{X}$ equals $3 \mathrm{X}$ and 3 equals $\mathrm{X}$, but it strongly agrees in the same way as $\mathrm{X}$ equals $3 \mathrm{X}$ because it strongly agrees to promote the usage of the AMOS package by SEM by R. B. Kline (2010). The expert retooled the scales such that they gave respondents a shifted chance to look at various options, thus improving the unwavering accuracy of the measure. Therefore, the collection of data is highly important for evaluating the reliability of the inquiry. though the inquiry is still ongoing, the number of people who are the managers or vicemanagers of the department of Central Area was 377 people from the public and private sectors KSA. The statistical study of the data was performed on clean and structured datasets of both SPSS and AMOS.

\section{Descriptive Analysis of The Respondents Background}

As can be seen in the table, the frequency of the statistical variables, such as Gender, Education, Sector, Years of experience, and Marital status, respondents from Saudi Arabia are mentioned in Table 1. The table indicates that Over 377 respondents, 312 valuable responses were obtained from the male ( 82.8 percent ) and 65 from the female (17.2 percent ). Therefore, it is the male of the population who dominates the sample of this report. Responders were requested to indicate their level of formal schooling. Taking into consideration the respondents' working field and job target, 28.1 percent of the respondents are working in the manufacturing industry; 25.4 percent work in the trade and retailing industry; 16.3 percent work in the service industry; 11.7 percent work in finance, accounting, or industry services; 9.4 percent work in construction industry; 6.1 percent work in education and health service industry; 5.9 percent work in government; 4.8 percent work in transport industry; 4.6 percent work in other industries; 4.4 percent work in agriculture and fishery; 3.4 percent work in public administration; 2.4 percent work in other services and communications; 1.7 percent work in agriculture, forestry and fishing; 1.5 percent work in real estate and renting and subleasing; 1 percent work in primary industry; and 0.9 percent work in other industries. 
As a consequence of the survey, $68.16 \%$ of respondents said that their job is serving in the government. Of the $31.83 \%$ of the working is private, they also specify their years' experience, as many also do. $27.6 \%$ of respondents had an experience of 5 years of age, $27.1 \%$ had an experience of 20 years of age, the $21.1 \%$ had an experience of at least 21 years. 15 years, $22 \%$ of the respondents were between the ages of 20 and 24, 10 years old and almost $4 \%$ of them were more than 21 years old, and respondents were even required to indicate their marital statuses. In adults age 18 and over, 95.8 percent of people were married, and 4.2 percent of them were single.

\section{Direct Effects of the Variables}

In order to assess the potential effects of the variables, the coefficient parameters estimates were tested as show in Table 2.

This table shows the results of the idealized influence and motivation. The idealized influence and individualized consideration were significant, as their values were significantly less than or equal to 0.05 . On other hand, the motivation Intellectual Stimulation wasn't significant, as their values were significantly less than or equal to 0.05 . Finally, $\mathrm{H} 1$ and $\mathrm{H} 4$ were supported however, $\mathrm{H} 2$ and $\mathrm{H} 3$ were rejected.

\section{Summary of Findings}

Direct Effects of Constructs, Hypothesis H1 was largely supported (ID $\rightarrow$ ED) the results showed there was a statistically significant relationship between the ID Idealized Influence and economic development (ED). Hypothesis H2 however, was rejected (MO $\rightarrow$ ED). Specifically, the results from the study showed there was no statistically significant relationship between Motivation (MO) and economic development (EC). Hypothesis H3 was rejected (IN $\rightarrow$ ED). Specifically, the results from the study showed there was no statistically significant relationship between, Intellectual Stimulation (IN) and economic development (EC). Hypothesis H4 however, was largely supported (IC $\rightarrow$ ED) the results showed there was a statistically significant relationship between (IC) Individualized Consideration and economic development. 


\section{Conclusion}

This study examined the relationship between transformational leadership, and economic development, and human and natural capital. The model was then checked against data from 377 managers in private and public sector companies in the Central area using advanced statistical software kits, such as SPSS version 18.0 and AMOS version 18.0. The conclusion of this analysis revealed that there was support for two hypotheses, but two of them were dismissed. Also noted in the study was that the growth of the managers' economic functions depended on their incorporation of these four variables (idealized influence, inspiring motivation, intellectual stimulation, and individualized consideration) in the economic structure and support of their strategies and changes. The participants in this study found that it is extremely desirable, but still effective for managers/teachers/professors/instructors to acquiring transformational and training programs. The findings from the study showed that organizations must support and collaborate with transformational leadership that will relate to the improvement of economic development. Based on the study's findings, transformational leadership has a significant influence on economic development, and it is recommended that organizations provide the necessary training to their leaders and managers, and recruiting manager managers who have skills leadership and management will contribute to effective leadership, extra efforts, satisfaction, and achieve economic development, which will contribute to the acquiring and maintaining of continuously high economic performances, and successfully carry out their organization tasks.

\section{Recommendations}

This research contributes to the body of evidence that explains the connection between transformational leadership in the middle east, and economic devlopment. The research also offers a better view of two new topics: transformational leadership in the workplace, and the industrial growth of various trade routes in coastal areas. This research offers useful insights into how businesses, and the administrators inside them, may take constructive measures to boost the economy. This research also is a part of the body of information that has been gained with relation to delivering resources and conceptual models that can educate present and prospective management on the best ways to better their outlook and provide a higher likelihood of success with their business objectives. 


\section{Suggestions for Future Studies}

This thesis studied the connection between transformational leadership, often called change leadership, and economic devlopment. When reviewed, several potential areas of study, moreover, remained to be discussed. Based on the analysis results and conclusions, a larger sample size, or a part of larger sample size, maybe studied to check the connection between both transformational leadership and transactional leadership. And also to check the relationship between educational growth and economic development with the same or larger sample size in a separate experiment. Also, given that this study was conducted with manager $\mathrm{s}$ and vicemanagers in Central Area and that this study used only Central Area managers, a similar and beneficial study may be conducted with managers in various parts of the country to assess whether this effect is different from country-to-country or culture-to-culture. A similar contribution to future research is to use the COVID-19 as an independent variable to measure the relationship between variables and to use as a mediator or moderator. As a basis of these perceivable experiences, consumers can begin to shape their expectations with the passing of time, exposure, and constant input from the surroundings (e.g., Venkatesh \& Davis, 2000, and F. Davis, 1989). Since this discovery of correlation was made by just a small number of children, it was quite premature to assume that all children would demonstrate the same results. Besides, it will be useful for potential studies to validate and investigate the model created for this analysis in other cultural environments, including other Asian or Western developed countries. This study provides interesting information about diverse cultures concerning the robustness of a research paradigm that has been applied almost everywhere. It was recognized that the robustness of the model could vary through various cultural contexts, therefore the model needs to be empirically validated, E. Mao \& P. Palvia (2006). And, this thesis collected data using a quantitative approach for gathering information. In the future, research may suggest using a qualitative style of qualitative knowledge gathering to ultimately learn more about economic development.

\section{References}

[1] Aliyu, A. A., Bello, M. U., Kasim, R., and Martin, D. (2014). Positivist and NonPositivist Paradigm in Social Science Research: Conflicting Paradigms or Perfect Partners? Journal of Management and Sustainability, 4(3), $79 . \quad$ doi: 10.5539/jms.v4n3p79. 
[2] Ananthan, S. S. (2014). A study of competencies and personality traits of successful leaders in the Malaysian banking industry and recommendations for averting a capacity gap. Dissertation, University of Hull, Hull, United Kingdom.

[3] Bass, B. M., and Avolio, B. J. (1997). Full range leadership development: Manual for the multifactor leadership questionnaire. Palo Alto, CA: Mind Garden.

[4] Bass, B. M., Avolio, B. J., Jung, D. I., Berson, Y. (2003). Predicting Unit Performance by Assessing Transformational and Transactional Leadership. Journal of Applied Psychology, 88(2), 207-18. doi: 10.1037/0021-9010.88.2.207.

[5] Beatty, A. L., S. Liao, and J. J. Yu. (2013). The spillover effect of fraudulent financial reporting on peer firms' investments. Journal of Accounting and Economics, 55 (2/3), 183-205. Doi:10.1016/j.jacceco.2013.01.003.

[6] Bellu, L. (2011). Development and development paradigms. A (reasoned) review of prevailing visions. FAO EASYPol Module 102. Rome, FAO. Available at: http://www.fao.org/3/a-ap255e.pdf

[7] Biech, E. (2008). The Pfeiffer book of successful team-building tools. San Francisco, CA: Pfeiffer.

[8] Burns, J.M, (1978). Leadership. New York: Harper and Row.

[9] Coates, J., and S. Srinivasan (2014). SOX after ten years: A multidisciplinary review. Accounting Horizons, 28(3),627-671. doi:10.2139/ssrn.2343108.

[10] Cooper, D. R., and Schindler, P. S. (2011). Qualitative research. Business research methods, 4(1), 160-182.

[11] Creswell, J. W. (1994). Research Design: Qualitative and Quantitative Approaches. Thousand Oaks. CA: Sage.

[12] Creswell, J. W. (2009). Research Design: Qualitative, Quantitative, and Mixed Methods Approaches (3rd ed.). Thousand Oaks, CA: Sage Publications.

[13] Daft, R.L. (2008) The Leadership Experience. 4th Edition, Thomson Corporation, Stamford.

[14] Davis, F. (1989). Perceived Usefulness, Perceived Ease of Use, and User Acceptance of Information Technology. MIS Quarterly, 13(3), 319-340. doi: 10.2307/249008.

[15] Downton, J.V. (1973). Rebel Leadership: Commitment and Charisma in the Revolutionary Process. New York, USA: Free Press. 
[16] Eliyana, Arif\& Muzakki, (2019 )Job satisfaction and organizational commitment effect in the transformational leadership towards employee performance. European Research on Management and Business Economics. DOI: 10.1016/j.iedeen.2019.05.001

[17] Gao, P., Zhang, G. (2019). Accounting Manipulation, Peer Pressure, and Internal Control. The Accounting Review, 94(1), 127-151. doi: doi.org/10.2308/accr-52078.

[18] Ge, W., A. Koester, S. McVay. (2017). Benefits and costs of Sarbanes-Oxley Section 404(b) exemption: Evidence from small firms' internal control disclosures. Journal of Accounting and Economics, 63(2/3),358-384. doi: 10.1016/j.jacceco.2017.01.001.

[19] Gleason, C. A., Jenkins, N.T., Johnson, W.B. (2008). The contagion effects of accounting restatements. The Accounting Review, 83(1), 83-110.

[20] Jotwani, D. (2018). Financial Development and Economic devlopment: Governance of Financial Institutions. International Journal of Business Ethics in Developing Economies, $7(2), 1-8$.

[21] Kirkland, K. L. (2011). The effect of emotional intelligence on emotional competence and transformational leadership. Dissertation. The City. University of New York, New York, United States.

[22] Kline, R. B. (2010). Principles and Practice of Structural Equation Modelling (3rd Ed.) New York, USA: Guilford Press.

[23] Kubiczek, P. (2016). Spin-triplet pairing in orbitally degenerate Anderson lattice model. Dissertation, Institute of Physics, Jagiellonian University, Kazimierz, Kraków, Poland.

[24] Kumari, R., Devadas, V. (2017). Modelling the dynamics of economic development driven by agricultural growth in Patna Region, India. Economic Structures, 6, 15. doi: 10.1186/s40008-017-0075-X.

[25] Leuz, C., and P. Wysocki (2016). The economics of disclosure and financial reporting regulation: Evidence and suggestions for future research. Journal of Accounting Research, 54(2), 525-622. doi:10.1111/1475-679X.12115.

[26] Levicki, C. (1998). The Leadership Gene. London: Financial Times, Pitman Publishing.

[27] Liu, W. (2018). Orientation and Effect Evaluation of Higher Education Features Based on Regional Economic Development Requirements - Henan Province. Educational Sciences: Theory and Practice, 18(6). 3819-3826. doi: 10.12738/estp.2018.6.295. 
[28] Mao, E., Palvia, P. (2006). Testing an Extended Model of IT Acceptance in the Chinese Cultural Context. ACM SIGMIS Database, 37, 20-32. doi: 10.1145/1161345.1161351.

[29] Miley, F.M, Read, A.F. (2017). Financial control, blame avoidance and Radio Caroline: Talking' 'bout my generation. Sage Journals, 22(3), 301-319. Doi: $10.1177 / 1032373216683527$.

[30] Nakabashi, L. (2018). Poverty and economic development: Evidence for the Brazilian states. EconomiA, 19(3), 445-458. Doi: 10.1016/j.econ.2018.11.002.

[31] Piontek, B. (2010). Contemporary determinants of socio-economic development (synthetic approach). Eco-Development Problems, 5(2), 117-124.

[32] Schroeder, J., M. Shepardson (2016). Do SOX 404 control audits and management assessments improve overall internal control system quality? The Accounting Review, 91(5), 1513-1541. Doi: 10.2308/accr-51360

[33] Sekaran, U., and Bougie, R. (2016): Research Methods For Business: A Skill Building Approach, (7th Ed.) New York, USA: John Wiley and Sons.

[34] Shamir, B., House, R.J., Arthur, M.B. (1993). The Motivational Effects of Charismatic Leadership: A Self-Concept Based Theory. Organization Science, 4(4), 577-594.

[35] Słodowa-Hełpa, M. (2015). Integral Development, Conditions, Scope, Challenges", CeDeWu, Warsaw 2013, Economic and Regional Studies, 8(2), 113-115.

[36] The General Organization for Social Insurance (GOSI), (2019): About GOSI Electronic Services. Retrieved from: https://www.gosi.gov.sa/GOSIOnline/About_GOSI_Electronic_Services\&locale=en_US.

[37] Venkatesh, V., Davis, F. (2000). A Theoretical Extension of the Technology Acceptance Model: Four Longitudinal Field Studies. Management Science, 46, 186-204. Doi: 10.1287/mnsc.46.2.186.11926.

Copyright (C) 2021 Dr. Fahad Saad Soliaman Algorabi Alharbi, Dr. Mazen Mohammed Farea, AJRSP. This is an open-access article distributed under the terms of the Creative Commons Attribution License (CC BY NC). DOI: doi.org/10.52132/Ajrsp.e.2021.251 